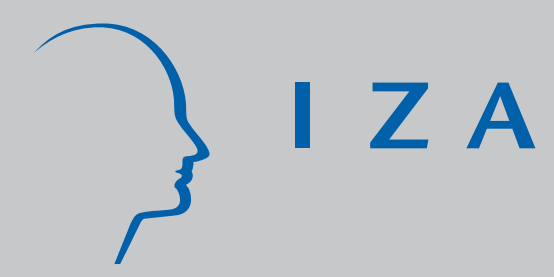

IZA DP No. 1830

The Gender Gap Reloaded: Is School Quality Linked to Labor Market Performance?

Spyros Konstantopoulos

Amelie Constant

November 2005 


\title{
The Gender Gap Reloaded: Is School Quality Linked to Labor Market Performance?
}

\author{
Spyros Konstantopoulos \\ Northwestern University and IZA Bonn
}

\section{Amelie Constant}

IZA Bonn

Discussion Paper No. 1830

November 2005

\author{
IZA \\ P.O. Box 7240 \\ 53072 Bonn \\ Germany \\ Phone: +49-228-3894-0 \\ Fax: +49-228-3894-180 \\ Email: iza@iza.org
}

\begin{abstract}
Any opinions expressed here are those of the author(s) and not those of the institute. Research disseminated by IZA may include views on policy, but the institute itself takes no institutional policy positions.

The Institute for the Study of Labor (IZA) in Bonn is a local and virtual international research center and a place of communication between science, politics and business. IZA is an independent nonprofit company supported by Deutsche Post World Net. The center is associated with the University of Bonn and offers a stimulating research environment through its research networks, research support, and visitors and doctoral programs. IZA engages in (i) original and internationally competitive research in all fields of labor economics, (ii) development of policy concepts, and (iii) dissemination of research results and concepts to the interested public.
\end{abstract}

IZA Discussion Papers often represent preliminary work and are circulated to encourage discussion. Citation of such a paper should account for its provisional character. A revised version may be available directly from the author. 
IZA Discussion Paper No. 1830

November 2005

\section{ABSTRACT \\ The Gender Gap Reloaded: Is School Quality Linked to Labor Market Performance?*}

This study examines the gender gap in wages of young adults in the late 1970s, mid 1980s, and 2000 , in the middle and the tails of the wage distribution using quantile regression. We also examine the importance of school quality indicators in predicting future labor market performance. We conduct analyses for three major racial groups in the US: Whites, Blacks, and Hispanics. We employ base year and follow up data from two rich longitudinal studies: the National Longitudinal Study (NLS) of high school seniors in 1972 and the National Education Longitudinal Study (NELS) of eighth graders in 1988. Our results indicate that school quality is an important predictor of and positively associated to future wages for Whites, but it is less so for the two minority groups. We confirm significant gender disparities in wages favoring men across three surveys in the 1970s, 1980s, and 2000 that are unaccounted for. While the unexplained gender gap is evident across the entire wage distribution, it is more pronounced for Whites and less pronounced for Blacks and Hispanics. Overall, the gender gap in wages is more pronounced in higher paid jobs (top 10 percent) for all groups, indicating the presence of a $\mathrm{n}$ alarming "glass ceiling."

JEL Classification: J16, J24, J31

Keywords: $\quad$ wages, gender differences, school quality, school effects, quantile regression

Corresponding author:

Amelie Constant

Institute for the Study of Labor (IZA)

Schaumburg-Lippe-Str. 7 / 9

53113 Bonn

Germany

Email: constant@iza.org

\footnotetext{
* We owe special thanks to Klaus F. Zimmermann and Larry V. Hedges for valuable comments and suggestions. We also appreciate the comments of David Ribar and Reeve Vanneman on earlier versions of this paper presented at the PAA 2005 and ESPE 2005. Lily Gataullina provided excellent student assistance. Financial support from the Volkswagen Foundation for the IZA project on "The Economics and Persistence of Migrant Ethnicity" is gratefully acknowledged.
} 
The study of gender differences in labor market outcomes, such as wages, has gained ample attention in economics and the social sciences. Gender differences in wages have been researched and documented, and frequently debated in the literature. It is an established fact that males earn substantially higher wages than females. There is some empirical evidence, however, that although the gender gap is decreasing over time due to women's increased labor force participation and the accompanied increase in their wages, it remains strong at the upper tail of the wage distribution. This gap has not been satisfactorily explained by the theory.

The quality of the empirical evidence has not always been very strong for two main reasons. First, typically, the samples of numerous studies on gender differences in wages are not representative of any well-defined population. Many studies use localized/convenience samples that are often times difficult to generalize to the nation as a whole. In addition, it is plausible that much of the previous research suffers from selection bias, which constitutes an important threat of external as well as internal validity (Cook and Campbell, 1979). The main argument against selection bias is that a sample of specific individuals might not be representative of the population of individuals with the same characteristics. It is impossible to know the extent of bias in these samples. However, it is conceivable that because of selection bias the estimates reported in most of the previous studies might be very different from their "true" population parameters. In other words, it is likely that some of the results reported are positively or negatively biased. 
Second, the overwhelming majority of previous studies on gender differences in wages has mostly examined and reported group differences in means (central tendency of the distribution of wages). Gender differences in the extremes (upper and lower tails) of the wage distribution are only recently documented in the literature. It is quite plausible that gender differences in the tails of the wage distribution may be quite different qualitatively than differences in the middle of the distribution. For example, males may be overrepresented in the top 10 percent of the wage distribution compared to females, a byproduct of over-concentration of men in highly paid jobs. Similarly, females may be overrepresented in the lower tail of the wage distribution. These differences may not necessarily be in congruence with gender differences on average.

This study employs base years and follow-up data of national probability samples of high school students in the US. Specifically, we use information from the base year (NLS:72), the fourth (NLS:79), and the fifth follow-up (NLS:86) of the National Longitudinal Study of the High School Class of 1972. We also use information from the second (NELS:92) and fourth follow-up (NELS:00) of the National Education Longitudinal Study of the Eighth Grade Class of 1988 (NELS:88). A main advantage of these data is that we can link characteristics of high schools attended to wages (from follow-up years), and thus, analyze school quality on wage differentials. In addition, these rich data allow us to examine the labor market performance of similarly aged individuals seven, eight, and fourteen years after high school graduation, and hence, likely avoiding transitional labor market effects. 
Because of the use of national probability samples our results are more likely to have higher external validity (generalizability), and be more resilient to threats of selection bias. We examine gender differences in hourly wages for young adults in the late 1970s, mid 1980s, and 2000 across the entire distribution of wages. Specifically, we employ quantile regression to determine the gender gap in hourly wages in the middle of the distribution as well as at the top and bottom 10 and 25 percent. We conduct separate analyses for three major race/ethnic groups in the US: Whites, Blacks, and Hispanics. This permits us to determine whether the gender gap differs by race/ethnic group and whether it is decreasing over time.

An equally important objective of the present study is to investigate the link between high school quality and labor market performance realized by hourly wages seven, eight, and fourteen years after high school graduation. Can high school quality predict future wages of young adults, net of the effects of individual characteristics such as high school performance, further educational attainment, potential work experience, occupation, marital status, and children? If so, then which educational inputs matter for the economic performance of young workers and for which ethnic groups?

Gauging the effects of school characteristics on the gender wage gap is important since school effects have differential and enduring effects on the earnings of individuals who attend different schools net of individual and family background characteristics (Constant and Konstantopoulos, 2003). Previous work on school effects has yielded mixed and inconsistent findings with respect to the importance of schooling on school outputs such as academic achievement. 
Some researchers have concluded that there is little or no evidence of school effects (Hanushek, 1986; 1989), while others report that the impact of school factors may be substantial (Greenwald, Hedges, and Laine, 1996).

The remainder of this study is structured as follows. First, relevant findings of previous research on the gender wage gap are summarized. Second, the data sets and the methods utilized are presented. Third, the results of the analyses are presented and discussed. Finally, we summarize and draw our conclusions.

\section{Related Literature}

Research on the gender wage gap has documented that, on average, the wages of white males are considerable higher than those of comparable females. Among the first researchers to examine the earnings differences between sexes is Oaxaca (1973) who used residual analysis and found the sex differential to be quite large. He concluded that a substantial proportion of the gender gap was attributable to the effects of discrimination, ( $77 \%$ for whites and $93 \%$ for blacks). A study on the gender wage gap in the Deep South in 1989 verifies that an alarming portion of the earnings gap is attributable to discrimination (Constant, 1993). That is, women are more qualified than the men but are not rewarded for their large stocks of human capital.

While all studies find that, on average, white male wages are considerably higher than those of white females it is also well established in the labor economics literature that gender effects are substantially larger than race/ethnicity effects (Carnoy, 1996; Durden and Gaynor, 1998; Corcoran and 
Duncan, 1979). A more recent study provides further support to this notion by reporting that schooling is important in explaining race but not gender wage differentials (England et al., 1999).

Blau and Beller (1988) find that the gender earnings gap in the US decreased among Whites and Blacks in the 1970s. Based on "offered wages" their study shows that the earnings of white women increased faster than the earnings of the black women. Yet, the total effect of occupational changes in the 1970s caused an increase in the gender earnings gap. In addition, these gender and race/ethnicity wage differentials persist even after adjusting for human capital and labor market characteristics; gender specific factors such as qualifications and discrimination play a significant role in determining the gender pay gap.

Nonetheless, the hourly wage difference between men and women has narrowed between the mid 1970s and the late 1980s (O'Neill and Polachek, 1993). The 1980s decline in the gender pay gap was, in fact, more dramatic than the decline in gender segregation (Cotter et al., 1995). Women of all considered races in this study have improved their earnings relative to white men.

The gender wage convergence is oftentimes partly attributed to increases in women's work experience, years of schooling, and other skill acquisition. Blau and Kahn (1997) postulate that the closure of the gender gap in wages during the 1980 s is not only attributed to improvements in women's occupational status and experience, but also to enhancements in women's unmeasured labor skills and/or a decrease in discrimination against them. Nonetheless, shifts in relative net supply, industrial restructuring and deunionization were more unfavorable for 
high-skilled than low- and middle-skilled women. Blau and Kahn (2000) find that two thirds of this wage gap is due to differences in experience, occupational choice, and industry classification. A rise in relative female productivity and a fall in female discrimination (the residual) have been contributing to the decrease in the gender wage gap.

Gill and Leign (2000) also demonstrate a decline in the gender wage gap between 1985 and 1994 in the US. They document that about 35 percent of the gap narrowing is due to the increase in women's week worked, job tenure, and full-time employment. Moreover, the authors show that the estimates of how education explains the narrowing of the gender wage gap heavily depends of the specification of the schooling variable; adding degree status, type of college, and major field of study increases the estimates of how education predicts the gender pay gap.

In general, the US exhibits a higher gender wage gap than other countries. A cross-country study among ten industrialized countries, including the US, shows that countries with a higher degree of wage centralization have lower levels of wage inequality (Blau and Kahn, 1996). Another study on the gender pay gap between the US and Sweden finds that it is the wage structure that affects the gender pay gap and explains cross-national differences (Blau and Kahn, 1997). This study also finds that the "traditional gender-specific factors do not appear to play a role in explaining the higher US gap" (p. 640).

Examining gender wage discrimination at quantiles in Spain, Gardeazabal and Ugidos (2005) find that gender wage discrimination is not constant across all quantiles of the wage distribution in 1995, and the highest level of gender wage 
discrimination is observed at the bottom of the wage distribution. In their study on gender wage gaps by education, de la Rica et al. (2005) use quantile regression and find that the wage gap in Spain increases along the wage distribution of men and women with tertiary education, in accordance with the conventional glass ceiling hypothesis. Yet, the gap is higher at the bottom than at the top for individuals with primary and secondary education. The authors argue that this is due to statistical discrimination exerted by employers.

Albrecht et al. (2004), using quantile regression decomposition techniques, confirm a gender wage gap in the Netherlands as well. They demonstrate that the average gender log wage gap for full-time employees is as high as 20 percent and it increases along the log wage distribution. Approximately a quarter of this gender gap can be attributed to differences in male and female labor market characteristics. The other three quarters can be ascribed to gender differences in rewards to those characteristics.

Looking at highly educated workers, Wood, et al. (1993) conclude that men and women lawyers fare differently, and after 15 years in the labor market women lawyers earn $60 \%$ less that men lawyers. They suggest that $11 \%$ of the overall log earnings gap "should be treated as the result of discrimination" ( $p$. 438). Bertrand and Hallock's (2001) study on the gender gap in top corporate jobs in the US finds that only 2.4 percent of all top executives in their sample are women, that, on average, female total compensation is $33 \%$ lower than male total compensation, and that middle-level managers suffer from a similar pay gap (46 percent). While occupational segregation is very important in explaining the gap, lower female participation in large firms explains one third of the gender 
wage gap. Accounting for all observable differences between men and women executives, they find that the unobservable gender wage differential is about 5 percent. Bell (2005) confirms the presence of the gender gap in wages of top executives in the US. Specifically, she finds that top women executives earn 8 to 25 percent less than top men executives. Bell also compares the gender wage differential in women led firms versus men led firms. Her empirical results indicate that in the establishments with female CEO or Chair, there are more female executives and these executives earn on average more than female executives in the male led firms.

Lastly, the black-white as well as the Latino-white median wage differential has decreased between 1940 and 1980 (Smith and Welch, 1986, 1989). Indeed, blacks and Latinos made large gains in education and wages during the last 50 years. During the 1980s, however, there was a slowdown in the Black/White wage convergence. In his study on differential educational quality, measured by pupils/teacher ratio, term length, percent of teachers with advanced degrees, and school size, Grogger (1996) finds that high school quality explains very little of the racial wage differential, net of schooling attainment. To conclude, even though gains in schooling contributed in reducing the minority-white wages gap, this contribution is rather small, especially for Blacks.

\section{Method}

\section{$\underline{\text { Data Sets }}$}

We employ two rich, longitudinal, and representative samples of high school students. Specifically, the first set of samples (NLS) includes individuals 
who were high school students in 1972 (the base year) and wage earners in 1979 and 1986 (the fourth and fifth follow-ups). The second set of samples (NELS) includes individuals who were eighth graders in 1988 (the base year), high school seniors in 1992 (second follow-up), and wage earners in 2000 (the fourth follow-up). These are rich data sets that contain detailed and valuable information on the high school the individual went to, the individual's performance in high school, and the individual's performance in the labor market. The other advantage in each of these data is that these individuals have all the same age, being high school seniors in the same year, and thus they all face the same macroeconomic junctures.

NLS:72 is a national probability sample of 22,583 high school seniors designed to represent all twelfth graders enrolled in public or private American high schools in the spring of 1972 (Riccobono et al., 1981). These students were followed for 14 years after high school, and, thus, they were resurveyed in 1974 , $1975,1977,1979$, and 1986. We employ data collected during the base-year survey in 1972, the fourth follow-up in 1979, and the fifth follow-up in 1986.

NELS:88 uses a two stage national probability sample of 24,599 eighth graders enrolled in public and private American schools in 1988. These students were followed for 12 years and hence were resurveyed in 1990, 1992, 1994, and 2000. In this study we use information from the second follow-up (NELS:92) when the students were high school seniors, and the fourth follow-up (NELS:00) eight years after high school graduation.

Both datasets are unique in providing valuable information on high school resources and quality, the educational attainment, occupational status, and 
employment outcomes of young adults. The longitudinal feature of the data allows us to examine the labor market performance of these individuals during their prime time in the labor market. In addition, because we are looking at individuals who have been in the labor market seven to fourteen years we may have avoided any biases from school to work transitions.

Our samples incorporate individuals with various levels of education and various occupations to ensure the inclusion of all persons who reported positive hourly wages in the follow up samples. However, military personnel and full time students are excluded from our samples. Our dependent variable is hourly wages in 1979, 1986, and 2000. In NLS, we decided to use the fourth follow-up as well for comparison purposes with the NELS:00 sample. Specifically, the average age in the NLS:86 sample is 32 years, while in NELS:00 it is 26 years. This six year difference is crucial for young adults and hence differences between these samples may be due to age differences. However, the average age of individuals in the NLS:79 sample is 25 years. This sample is more comparable age-wise to the fourth NELS follow-up in 2000, and detecting differences should not be due to age differences. Note that we use the year 1979 as the base year of wage calculation and deflate the wages of the years 1986 and 2000 accordingly.

\section{Analysis}

\section{Important Correlates of Wages}

Wages are a function of education, training, health, and experience in the labor market. According to human capital theory, education enhances labor 
market productivity and, therefore, wages (Becker, 1964). In fact, education is pivotal to human capital formation, and investments in human capital have been hypothesized to yield sizable economic and social rates of return. The main hypothesis is that higher levels of education correspond to higher levels human capital, which in turn results in higher labor market performance and higher paying jobs. To that end, we explore gender and racial differences in wages controlling for educational attainment. Given that the individuals in this study have finished high school, we control for educational attainment using a dummy that takes the value of one if the individual has a college degree or more and zero otherwise. We also control for potential experience in the labor market. Potential experience is calculated as (Age - education - 6). It captures general training, specific on the job training, and tenure or seniority. We expect more years of labor market experience to increase wages albeit at a decreasing rate.

According to human capital theory, it is the different investments in human capital (schooling and work experience) that lead to wage disparities. Married women and mothers in particular, bear the cost of family responsibilities and have fewer opportunities to invest in human capital. Women's intermittent labor force participation and its subsequent decay in skills is certainly one culprit for the persistent gender wage gap.

We also examine gender differences in wages controlling for occupational status using two dummies: one for professional and one for white-collar workers. The blue-collar workers category serves as the comparison group. Occupational status is a proxy for choices and preferences in the labor market (Mutari and Figart, 2003). It is also a proxy of the market's evaluation of an individual's skills 
and potential. We are interested in determining gender differences in wages net of the effects of occupational status, or examine the gender gap for individuals with the same occupational status.

Previous findings have reported that marital status is an important correlate of wages. In principle, marital status conveys stability and commitment, signals productivity to the labor market, and affects potential tenure on the job, hence positively affecting wages. It has been repeatedly found that in the U.S. married men earn substantially more than unmarried men even after controlling for human capital and race (Bartlett and Callahan, 1984; Korenman and Neumark, 1991). More recent studies have replicated these findings in other developed countries suggesting that the married-unmarried men gap in average wages might be ubiquitous (Schoeni, 1995). In fact, Schoeni reported that wage differences are evident even among those men who are currently not married. For example, separated or widowed men earn significantly more than men who are never married. For that reason, we also examine gender differences in wages net of the effects of marital status. We control for marital status using a dummy that takes the value of one if the individual is married or living under common law and zero otherwise. We also control for the number of children because mothers are often penalized in the labor market. Elliott and Parcel (1996) find that non-black women who are mothers have lower hourly wages than non-mothers, controlling for labor force participation and the characteristics of their occupations.

A contribution in this study is that we also study the role of school quality in the determination of wages. We include school quality identifiers in the wage 
regression. In particular, we include in the wage regression four important attributes that capture high school quality and can be directly measured from the surveys. Namely, these are: (i) the percent of high school graduates who go to college, (ii) the percent of teachers with graduate degrees, (iii) the average school achievement, and (iv) the average school socioeconomic status (SES). All four variables indicate school quality and we hypothesize that higher levels of these variable indicate higher high school quality, which in turn has a positive impact on wages. However, school quality may have differential impacts on the wage of minorities.

\section{Estimation Strategy}

The unit of our analysis is the individual. In our surveys we only observe the wages of those who are working. Since workers may differ from non-workers in unobservable ways we need to adjust our models for possible selection bias. This issue is very important especially when studying women who may not be as strongly attached to the labor market as men. Following Heckman (1979) we first estimate a probit model on the labor force participation for the entire sample (workers and not workers). Our binary outcome in this exercise is working (partor full-time) or not.

The predictors of the labor force participation equation include gender, family background (i.e., socioeconomic status of the person's family), educational attainment of the individual, marital status of the individual, family size (i.e., number of children), sources of non-labor income, and high school grades. Since most of these predictors may have differential effects on gender, we also 
include all possible interactions between gender and the remaining predictors as additional controls. We hypothesize that a college degree will increase the probability to work, while high non-labor income will decrease the probability to work by increasing the reservation wage of the individual. In addition, we expect married individuals to have a higher probability to work since marital status has been shown to signal labor force attachment and higher productivity in the labor market affecting potential tenure on the job (Korenman and Neumark, 1991). Note that while this argument holds for men it does not hold for women. Married women usually suffer from employers' statistical discrimination, viewed as having a higher probability of quitting since they continuously face the choice of family or career.

From the probit model we calculate the inverse Mill's ratio or lambda (?), which we take into account in the wage regression to adjust for possible nonrandom selection of workers. All analyses are corrected for selection in the labor force, and therefore all results presented in this study are adjusted for potential selection bias. The outcome variable is the log of hourly wages adjusted for different years. The wage regression is fine tuned to take care of identification issues. It includes the following predictors: educational attainment, marital status, family size (.e., number of children), occupation, estimated work experience, high school grades, and four school related predictors that measure school quality. Specifically, the school predictors include average school achievement, average school SES, the percentage of high school graduates that go to college, and the percentage of teachers with graduate degrees. All school predictors are hypothesized to indicate school quality and are expected to be positively and 
significantly associated with hourly wages. In the ensuing analyses we thus consider one-tail significance tests. Note that in this regression we do not include the gender dummy, or any interactions. That is, we assume that men and women are alike. We only identify the common factors. We obtain robust standard errors on all estimates to account for heteroskedasticity.

Once we run the wage regressions, we compute the residuals and use them as the new outcome variable to examine gender differences. With this procedure, we take out all common effects between men and women. The residuals now contain all that is different between men and women. This is the unexplained part in wages. Our goal is to examine the gender wage gap across the entire distribution. To that end, we use quantile regression and regress the residuals from the hourly wage estimation on gender. Quantile regression is a widely used econometric method (Koenker and Bassett, 1978). This semiparametric approach allows the estimation of gender differences in hourly wages at various points of the distribution. Quantile regression can be perceived as a robust regression method that allows estimation in cases where the normality assumption of the error terms is not tenable (Koenker and Bassett, 1978; Bushinsky, 1998).

Recently, quantile regression has been used largely as a tool of providing information across the entire distribution of a continuous dependent variable (Bushinsky, 1998). We hypothesize that the wage gap is not uniformly distributed across the wage distribution. Gender differences in hourly wages in the tails of the distribution might be qualitatively different than differences in the middle. In addition, the gender wage gap may be larger in the upper tails than in 
the lower tails. Again, we obtain robust standard errors for all gender estimates to account for heteroskedasticity, through bootstrapping .

Finally, we also examine gender differences in the variability of the hourly wage distributions. Differences in the variability of the distribution of earnings among groups are gauged using the variance ratio (Hedges and Nowell, 1999). This ratio is simply the square of the ratio of the standard deviation of the wages distribution for women to that of the wages distribution for men. A ratio greater than one indicates that the variance of the wage distribution for women is larger than that for men, while a ratio smaller than one indicates that the variance of the wage distribution for men is larger. The variance ratios are computed using the residuals from the wage regression. Specifically, we compute the variance of these residuals for men and women separately for all surveys, and then create the variance ratios.

Results and Discussion

\section{Descriptive Statistics}

Table 1 summarizes the descriptive statistics for selected variables in the three samples by race/ethnicity and gender. These statistics are weighted appropriately to ensure representativeness. In the NLS samples white and blue collar jobs are the two most popular categories. In NELS however, a higher proportion of workers is in professional rather than in blue collar jobs. Women are more likely to work in white collar or professional jobs, and men are more likely to work in blue or white collar jobs. It is interesting that in 2000 , the men in 
our sample are almost equally likely to work in white, blue collar, or professional jobs. In NLS the overwhelming majority of individuals are married, while in NELS most of the individuals are single. Given that individuals in NLS:79 and NELS:00 have comparable ages this indicates that in $\mathbf{2 0 0 0}$ young adults were more likely to be single in their mid 20 s than in 1979 . Women are consistently more likely to be married or divorced, separated, or widowed than men. In contrast, men in our samples are more likely to be single.

\section{Insert Table 1 Here}

Overall, nearly one quarter of the individuals in our sample have a college degree or more. While in NLS men are more likely to have at least a college degree, in NELS:00 it is the women who are more likely to have at least a college degree. These raw statistics show that hourly wages for Whites are consistently larger than the wages for minority groups across all surveys. The hourly wages of men are also consistently larger than the wages of women across all surveys. Overall, the gender gap in hourly wages seems to be more pronounced for Whites; for example, in 2000 men earned on average $\$ 8.5$ per hour more than women. It is interesting that the gender gap is somewhat smaller for Hispanics ( $\$ 5.5$ per hour) and even smaller for Blacks ( $\$ 4.0$ per hour).

\section{School Quality Effects}

Table 2 summarizes the associations between the indicators of school quality and hourly wages controlling for important covariates for Whites, Blacks, 
and Hispanics. The school quality predictors in the selection adjusted wage regressions are slightly to moderately correlated with each other (the highest correlation is nearly 0.5 ) but there is no evidence of collinearity in our regression models. Overall school quality seems to have a higher predictive efficacy in the wage regression of the white samples. For Whites, all school quality coefficients are significant at least once across surveys. With few exceptions that are not significant, the associations are positive, as expected, indicating that higher levels of high school quality induce higher hourly wages in the future. In NLS, 75 percent of the school quality coefficients are significant and positively related to future hourly wages. The results for both NLS samples are qualitatively similar, as expected.

Insert Table 2 Here

Specifically, White individuals who went to a high school that has a high percentage of its graduates going to college, a high SES, and employs a high percentage of teachers with graduate degrees earn more in NLS:79 and NLS:86 than those who did not go to such schools. The school SES variable has the highest impact on wages; it increases wages by 11 to 15 percent in 1979 and 1986 respectively, all else being equal. This indicates a serious and enduring impact of school SES on wages, even 14 years after high school graduation. The school SES variable is also a strong determinant in NELS:00 for Whites. That is, those who went to a high school with high SES earn 21 percent more than those who did not, all else being equal. Unlike the NLS samples, average 
school achievement is also a significant predictor of wages in NELS:00. That is, Whites who attended high achieving high schools in 1992, had higher hourly wages in 2000 , all else being equal.

Interestingly, the school quality indexes are not as important for the wages of Blacks. This is consistent with the results of Grogger (1996) although he used different school quality measures. Only in NLS:86 the percentage of teachers with graduate degrees is significantly and positively associated with the hourly wages for Blacks, albeit of a small size. Ninety percent of the coefficients are not significant, and it appears that school quality is less important for Blacks than for Whites with respect to labor market performance. The estimation results for Hispanics are comparable to those reported for Blacks. None of the school quality coefficients are significant in NLS:79 suggesting that high school quality may not be as important for the Hispanics' future labor market performance. It is encouraging, however, that in NLS:86 the wages of Hispanics, who went to a school with a high percentage of teachers with graduate degrees, are significantly higher than the wages of those who did not go to such schools. Although the percent increase is small (03 percent). In NELS:00 50 percent of the school quality effects on the wages of Hispanics are positive and significant. While both the percentage of high school graduates in college and school SES are highly significant and positive predictors of hourly wages it is the latter that increases wages by 31 percent, all else equal. ${ }^{1}$ Hence, it appears that high school SES affects wages of Whites and Hispanics considerably in 2000.

\footnotetext{
${ }^{1}$ The Mills ratio is negative and significant in all specifications, indicating that selection adjustment was necessary. The workers in our sample appear to be negatively selected to the labor market.
} 
Nonetheless, the Black and Hispanic samples are much smaller than the samples of Whites, and across all surveys the standard errors of the school quality coefficients are consistently larger for the Black and Hispanic samples (two to three times). This indicates that failure to detect significant coefficients in Black and Hispanic samples may be due to the smaller statistical power of the $t$ tests. For example, observe the coefficients for percent of teachers with graduate degrees in NLS:79. Even though the coefficients for Blacks and Hispanics are larger, the effects are not significant. This is due to the fact that the statistical power of the test is 0.75 for Whites, but only 0.34 and 0.23 for Blacks and Hispanics respectively. Hence, the probability of detecting a significant association, if it exists, is two to three times smaller for Blacks and Hispanics.

Overall, these results indicate that high school quality is important for the future remuneration of Whites in the labor market. The school SES variable is the most important determinant of wages for Whites in terms of percent increase. The importance of school quality for the two minority groups is not consistently demonstrated. Only the percent of teachers with graduate degrees is important for the wages of Blacks. The school SES offers a high premium to the wages of Hispanics, while the percent of teachers with graduate degrees and percent of high school graduates in College seem useful predictors of their wages as well.

We also conducted analyses using different coding for school quality variables, such as average SES and achievement, to examine possible non linear effects. Overall, the results obtained from these specifications are qualitatively similar to those reported here. 


\section{The Gender Wage Gap}

In Table 3 we present the results on the gender differences in adjusted or residual hourly wages adjusted for important predictors for the three race/ethnic groups. We perform this exercise for the middle and the top and bottom 10 and 25 percent of the wage distribution. For Whites, all gender coefficients are negative indicating that males earn more per hour than females across the entire distribution of hourly wages. Nearly 90 percent of these gender coefficients are significant in all three surveys. The gender gap in hourly wages is consistently larger in the middle and the upper tails of the hourly wage distribution. In NLS:79 and NELS:00, in particular, the wage gap is the largest at the top 10 percent with women earning about 16 percent less than men. In NLS:86 the wage gap is the largest at the top 10 and 25 percent of the hourly wage distribution, with women earning 11 percent less than men.

\section{Insert Table 3 Here}

Recall that these results are obtained after we controlled for all observables and took out all common effects between men and women. These estimates indicate more pronounced gender differences in the higher paid jobs that are unexplained. In sum, for the top 10 percent of the wage distribution, while the white gender gap was reduced in the 1980s it increased again in 2000 . For the rest of the quantiles, our results show a steady decline in the gender wage gap from the 1970 s to 2000 . 
We find similar results for the gender gap in Blacks. All of the gender coefficients (except one) are negative indicating that black men earn more than black women per hour across the entire distribution of wages. However, only about 50 percent of the gender coefficients are statistically significant. The gender gap in the middle of the distribution is consistently significant and negative across all surveys (favoring men). The gap is smaller in the lower tail (except for the bottom 10 percent in NELS) and larger in magnitude in the upper tail (for NLS:79 and NLS:86). The largest wage gender disparity occurs at the top 10 percent of the NLS:86 with a significant coefficient of 0.266 . This indicates an alarming glass ceiling for Blacks. However, it is in the middle and the top 25 percent where we find the most significant gender disparities across all surveys. Black women earn consistently less than comparable black men. Note that at the top 25 percent, the wage gender gap is reduced from 15 percent in the late 1970s to 11 percent in the mid 1980s and stayed the same in 2000 . It is interesting that in NELS:00 we also find a large wage gap at the bottom 10 percent, with women earning 19 percent less than men.

In contrast to Whites and Blacks, the gender wage gap is less pronounced for Hispanics at least in terms of significance levels. In the lower tails (both at the 10 and 25 percent) of the hourly wage distribution the gap is small and not significant. In fact, the gender coefficients are mainly positive suggesting that Hispanic women earn more per hour in lower paying jobs than comparable men. In NLS:86 and NELS:00 all gender coefficients in the middle and the upper tails of the wage distribution are negative (favoring men). Only in NLS:86 and in the middle and upper tail the gender wage gap reaches statistical significance 
favoring males. It is noteworthy, that in both NLS:86 and NELS:00 Hispanic males earn significantly more per hour in higher paid jobs than their female counterparts. Hispanic women earn 12 percent less than comparable men at the top 25 percent. The gap is even larger at the top 10 percent in NLS:86 (18 percent). As with Whites and Blacks, the gender disparity that is unexplained is a lot larger at the upper tail of the hourly wage distribution.

Overall, we find that the standard errors of the gender coefficients are larger at the tails of the wage distribution. This indicates that, other things being equal, there is a lower chance of detecting significant differences in the tails (since the power of the statistical test is lower). In addition, the standard errors of the gender gap coefficients for Blacks and Hispanics are consistently larger than those obtained for Whites. Hence, there is a lower chance of detecting significant gender wage differences for Blacks and Hispanics than for Whites (due to statistical power again).

\section{Differences in Variability}

Differences in the variability of the wage distribution can provide important information about the gender gap. For example, the hourly wage distributions for men and women may have comparable means, but different variances. A larger variation indicates that there are more individuals in the lower and upper tails of the wage distribution. From previous work we know that males have much more spread out distributions in school outputs, such as academic achievement (Hedges and Nowell, 1995). Since, wages can be thought of as a longer term 
school output we examine the variation of wages for men and women to determine differences in variability.

Table 4 presents the results on gender differences in the variability of the wage distribution. For Whites, the wage distributions for men and women have comparable variances. The variance ratios are close to one indicating gender parity in wage variation across all surveys. For Blacks, we find that men have consistently more spread out wage distributions than women, since all variance ratios are smaller than one. For Hispanics, gender differences in variability are more pronounced. In NLS:79 and NELS:00 the wage distribution for men is more spread out than that for women. In NLS:86 however, the variance ratio is greater than one indicating larger variation in the wage distribution for women.

Insert Table 4 Here

\section{Conclusion}

In this study we revisit the gender wage gap for three race/ethnicity groups in the US over three decades, using important school quality determinants and a novel estimation technique. Our goal is four fold: (i) to see how the gender wage gap changes with race/ethnicity for Whites, Blacks, and Hispanics, (ii) to see if the gender wage gap decreases, increases or remains the same through the last four decades, (iii) to see whether the gender wage gap is larger or smaller at the tails of the wage distribution, compared to the middle, and (iv) to see whether 
school quality has an indelible impact on the future wages of young adults in the labor market.

We employ two nationally representative data sets, the NLS and NELS, which span across four decades. One of the advantages of these data is that, in the base year, all individuals are of the same age thus avoiding any cohort effects. Both datasets are unique in providing valuable information on the high school quality, educational attainment, occupational status, and employment outcomes of young adults. The longitudinal feature of the data allows us to examine the labor market performance of these individuals during their prime time in the labor market, while avoiding any biases from school to work transitions. In addition, both datasets are part of the National Education Longitudinal Studies program instituted by the National Center of Education Statistics with the objective to study the educational, vocational, and personal development of young people. Hence, these data provide unique opportunities to study young adults.

In our estimation technique we control for selection into the labor force, applying the Heckman procedure, and we identify the common factors between men and women in hourly wages. In this exercise we control for high school quality. We then compute the residuals, which now contain all that is different between men and women. This is the unexplained part. Using quantile regression we regress these residuals from the wage regression on gender, and correct the standard errors.

First, we find that high school quality is an important predictor and positively associated to the hourly wages of young men and women. This result 
is mainly found for Whites. The school SES variable is the most important in increasing wage returns both in magnitude and significance. It also has an enduring and long-lasting effect on the wages of white workers. However, high school quality is not as important for the wages of the two minority groups with three exceptions. The percentage of teachers with graduate degrees variable is significant for the wages of Blacks and Hispanics in 1986, albeit of a small size, the school SES variable is highly significant and of a large size for Hispanics in 2000 , and the percentage of high school graduates in college is also significant for Hispanics in 2000 . In all cases, school quality increases hourly wages.

In comparison to Whites, however, these finings are alarming since they indicate that high schools do not matter much regarding the future labor market performance of minority groups. If one assumes that there is differential attrition among the three groups and that Blacks and Hispanics are more likely to dropout of high school, these results become even more discouraging since, at best, they indicate trivial school effects for the "best" students of the minority groups.

In addition, our results confirm significant gender disparities in hourly wages favoring men across three surveys in the 1970s, 1980s, and 2000 that are unaccounted for. These disparities are more pronounced for Whites, and less pronounced for Blacks and Hispanics in that order. However, a consistent finding is that the magnitude of the gender gap is always larger in the upper tails of the hourly wage distribution for all race/ethnic groups. That is, women earn, overall, less than men in highly paid jobs, consistent with the glass ceiling hypothesis. 
In sum, for the top 10 and 25 percent of the wage distribution of Whites, women earn about 16 and 11 percent less than men respectively, and this is unexplained. While the white gender gap was reduced in the 1980s it increased again in 2000 . For the rest of the quantiles, our results show a steady decline in the gender wage gap from the 1970 s to 2000 . For the wage distribution of Blacks, we find a considerable gap at the top 10 percent in 1986 . At the top 25 percent, the wage gender gap for Blacks is reduced from 15 percent in the late 1970s to 11 percent in the mid 1980s and stayed the same in 2000 . It is interesting that in 2000 we also find a large wage gap at the bottom 10 percent, with women earning 19 percent less than men. For the wage distribution of Hispanics, women at the top 10 percent earn 18 percent less than their male counterparts.

Lastly, we find gender parity in the wage variation across all surveys for Whites. For Blacks, we find that men have consistently more spread out wage distributions than women, and for Hispanics, gender differences in variability are more pronounced. 


\section{References}

Albrecht, J. W., A. van Vuuren, and S. Vroman. 2004. Decomposing the Gender Wage Gap in the Netherlands with Sample Selection Adjustments. IZA Discussion Paper No. 1400.

Becker, G. S. 1964. Human Capital: A Theoretical and Empirical Analysis with Special Reference to Education. New York: Columbia University Press.

Bartlett, R L. and C. Callahan. 1984. Wage Determination and Marital Status: Another Look. Industrial Relations 23: 90-96.

Bell, L. A. 2005. Women-Led Firms and the Gender Gap in Top Executive Firms. IZA Discussion Paper No.1689.

Bertrand, M. and K. Hallock. 2001. The Gender Gap in Top Corporate Jobs. Industrial and Labor Relations Review 55: 3-21.

Blau, F. D. and A. H. Beller. 1988. Trends in Earnings Differentials by Gender (1971-1981). Industrial and Labor Relations Review 41: 513-529.

Blau, F. D. and A. H. Beller. 1992. Black-White Wages over the 1970 s and 1980s: Gender Differences in Trends. The Review of Economics and Statistics 74: 276-86.

Blau, F. D. and L. M. Kahn. 1996. Internal Differences in Male Wage Inequality: Institutions versus Market Forces. Journal of Political Economy 104: 791837.

Blau, F. D. and L. M. Kahn. 1997. Swimming Upstream: Trends in the Gender Wage Differential in the 1980s. Journal of Labor Economics 15: 1-42.

Blau, F. D. and L. M. Kahn. 1999. Analyzing the Gender Pay Gap. The Quarterly Review of Economics and Finance 39: 625-646. 
Gender Differences in Wages 31

Blau, F. D. and L. M. Kahn. 2000. Gender Differences in Pay. Journal of Economic Perspectives 14: 75-99.

Bushinsky, M. 1998. Recent Advances in Quantile Regression Models: A Practical Guideline for Empirical Research. The Journal of Human Resources 33: 89-126.

Carnoy, M. 1996. Education and Racial Inequality: The Human Capital Explanation Revisited. Economics of Education Review 15: 259-72.

Cohen, J. 1977. Statistical Power Analysis for the Behavioral Sciences. New York: Academic Press.

Constant, A. and S. Konstantopoulos. 2003. School Effects and Labor Market Outcomes for Young Adults in the 1980s and 1990s. Applied Economics Quarterly 49: 5-22.

Constant, A. 1993. Male-Female Wage Disparity in the Deep South. Unpublished monograph.

Cook, T. D. and D. T. Campbell. 1979. Quasi-experimentation. Boston, MA: Houghton Mifflin.

Corcoran, M. and G. J. Duncan. 1979. Work History, Labor Force Attachment, and Wages Differences between the Races and Sexes. Journal of Human Resources 140: 3-20.

Cotter, D. A., J. M. DeFiore, J. M. Hermsen, B. Marsteller Kowalewski, and R. Vanneman. 1995. Occupational Gender Segregation and the Earning Gap: Changes in the 1980s. Social Science Research 24: 439-454. 
de la Rica, S., J. J. Dolado, and V. Llorens. 2005. Ceiling and Floors: Gender Wage Gaps by Education in Spain. IZA Discussion Paper No.1483.

Durden, G C. and P. E. Gaynor. 1998. More on the Cost of being Other Than White and Male: Measurement of Race, Ethnic, and Gender Effects on Yearly Wages. American Journal of Economics and Sociology 57: 95-103.

Elliott, M. and T. L. Parcel. 1996. The Determinants of Young Women's Wages: Comparing the Effects of Individual and Occupational Labor Market Characteristics. Social Science Research 25: 240-259.

England, P., K. Christopher, and L. L. Reid. 1999. Gender, Race, Ethnicity, and Wages. In Latinas and African American Women at Work, edited by Irene Browne, pp 139-182. New York: Russell Sage.

Gardeazabal, J. and A. Ugidos. 2005. Gender Wage Discrimination at Quantiles, Population Economics 18: 165-180.

Gill, A. M. and D. E. Leign. 2000. Community College Enrollment, College Major, and the Gender Wage Gap. Industrial and Labor Relations Review 54: 163-181.

Greenwald, R., L. V. Hedges, and R. Laine. 1996. The Effects of School Resources on Student Achievement. Review of Educational Research 66: 361-396.

Grogger, J. 1996. Does School Quality Explain the Recent Black/White Wage Trend? Journal of Labor Economics 14: 231-253.

Hanushek, E. A. 1986. The Economics of Schooling: Production and Efficiency in Public Schools. Journal of Economic Literature 24: 1141-77. 
Hanushek, E. A. 1989. The Impact of Differential Expenditures on School Performance. Educational Researcher 18: 45-51.

Heckman, J. J. 1979. Sample Selection Bias as a Specification Error. Econometrica 47: 475-492.

Hedges, L V., and A. Nowell. 1995. Sex Differences in Mental Test Scores, Variability, and Numbers of High Scoring Individuals. Science 269: 41-45.

Hedges, L. V., and A. Nowell. 1999. Changes in the Black-White Gap in Achievement Test Scores. Sociology of Education 72: 111-135.

Koenker, R. and Bassett, G. 1978. Regression Quantiles. Econometrica 46: 3350.

Korenman, S. and D. Neumark. 1991. Does Marriage Really Make Men More Productive? Journal of Human Resources 26: 282-307.

Mutari, E. and D. B. Figart. 2003. Women and the Economy. Armonk, NY: M. E. Sharpe.

Oaxaca, R. 1973. Male-Female Wage Differentials in Urban Labor Markets. International Economic Review 14: 693-709.

O’Neill, J. 1990. The Role of Human Capital in Wages Differences between Black and White Men. Journal of Economic Perspectives 4: 25-45.

O’Neill, J. and S. Polachek. 1993. Why the Gender Gap in Wages Narrowed in the 1980s. Journal of Labor Economics 11: 205-28.

Riccobono, J., L. B. Henderson, G. J. Burkheimer, C. Place, and J. R. Levinsohn. 1981. National Longitudinal Study. Research Triangle Institute. Schoeni, R. F. 1995. Marital Status and Wages in developed Countries. Journal of Population Economics 8: 351-59. 
Smith, J. and F. R. Welch. 1986. Closing the Gap: Forty Years of Economic Progress for Blacks. Santa Monica, CA: Rand Corp.

Smith, J. and F. R. Welch. 1989. Black Economic Progress after Mydral. Journal of Economic Literature 27: 519-64.

Wood, R. G., M. E. Corcoran, and P. N. Courant. 1993. Pay Differences among the Highly Paid: The Male-Female Earnings Gap in Lawyers' Salaries. Journal of Labor Economics 11: 417-441. 
Gender Differences in Wages 35

Table 1.

Arithmetic Means and Proportions for Selected Variables: NLS:79, NLS:86 and NELS:00

Variables of Interest $\quad \underline{\text { NLS:79 }} \quad \underline{\text { NLS:86 }}$

Female Male

NELS:00

U.S. Population Female Male

U.S. Population Fema

Male

\section{Gender}

Female

Male

$50.2 \%$

$50.8 \%$

$49.2 \%$

$49.8 \%$

$49.8 \%$

$\begin{array}{lll}8.8 \% & 10.5 \% & 7.2 \% \\ 4.1 \% & 3.9 \% & 4.3 \%\end{array}$

$9.5 \%$

$11.0 \% \quad 7.9 \%$

$13.0 \%$

$12.2 \% \quad 13.8 \%$

Hispanic

White

$82.4 \%$

$80.8 \% \quad 83.9 \%$

$3.3 \%$

$3.1 \% \quad 3.5 \%$

$11.4 \%$

$11.8 \% \quad 11.1 \%$

Occupation

Professional

White Collar

Blue Collar

Self Employed

\section{Education}

College Degree or More

$31.8 \%$

$29.6 \% \quad 34.0 \%$

$25.9 \%$

$24.5 \% \quad 27.5 \%$

$28.2 \%$

$31.5 \%$

$25.0 \%$

\section{Marital Status}

Single

Married

Divorced-Separated-Widowed

Living in Common Law

$\begin{array}{ccccccccc}37.5 \% & 31.6 \% & 43.5 \% & 17.0 \% & 15.1 \% & 18.9 \% & 52.4 \% & 46.0 \% & 58.7 \% \\ 52.8 \% & 56.8 \% & 48.7 \% & 67.7 \% & 68.1 \% & 67.5 \% & 39.7 \% & 44.4 \% & 35.0 \% \\ 9.7 \% & 11.6 \% & 7.8 \% & 10.4 \% & 12.2 \% & 8.6 \% & 6.9 \% & 8.8 \% & 5.1 \% \\ - & - & - & 3.9 \% & 3.9 \% & 3.9 \% & 1.0 \% & 0.9 \% & 1.2 \%\end{array}$


Gender Differences in Wages 36

Table 1.

Arithmetic Means and Proportions for Selected Variables: NLS:79, NLS:86 and NELS:00

School Quality

Percent of Graduates in College

$49.6 \%$

$49.1 \% \quad 50.1 \%$

$48.1 \%$

$47.5 \% \quad 48.8 \%$

$43.8 \%$

$43.1 \% \quad 44.4 \%$

Hourly Wages

All Groups

Whites

Blacks

Hispanics

$\mathrm{N}$

Note: own calculations using weights

\begin{tabular}{lllllllll}
6.0 & 5.2 & 6.8 & 21.8 & 18.5 & 25.1 & 32.4 & 28.6 & 36.0 \\
6.1 & 5.2 & 6.8 & 21.9 & 18.3 & 25.2 & 33.7 & 29.5 & 38.0 \\
5.6 & 5.1 & 6.3 & 17.3 & 16.3 & 18.8 & 28.0 & 25.8 & 29.8 \\
5.8 & 4.8 & 6.7 & 21.3 & 19.0 & 23.3 & 29.3 & 26.6 & 32.1 \\
& & & & & & & & \\
4,441 & 7,519 & 6,912 & 14,131 & 7,358 & 6,764 & 12,144 & 6,362 & 5,782 \\
\hline
\end{tabular}


Table 2.

Gender Differences in Wages 37

Selection Adjusted Wage Estimates of School Effects

NLS:1979

\begin{tabular}{lccc}
\cline { 2 - 4 } & Whites & Blacks & Hispanics \\
\hline Variables & Coefficient & Coefficient & Coefficient \\
& (standard error) & (standard error) & (standard error) \\
\hline Percent of High School Graduates in College & $0.002^{* *}$ & 0.001 & -0.003 \\
& $(0.0005)$ & $(0.001)$ & $(0.002)$ \\
Percent of Teachers with Graduate Degrees & $0.0007^{\star *}$ & 0.001 & 0.002 \\
& $(0.0003)$ & $(0.001)$ & $(0.002)$ \\
Average School Achievement & -0.0004 & 0.0003 & 0.008 \\
Average School SES & $(0.0018)$ & $(0.004)$ & $(0.007)$ \\
& $0.112^{* *}$ & -0.036 & -0.127 \\
& $(0.039)$ & $(0.154)$ & $(0.289)$
\end{tabular}

NLS:1986

\begin{tabular}{lccc} 
& Whites & Blacks & Hispanics \\
\cline { 2 - 4 } Variables & Coefficient & Coefficient & Coefficient \\
& (standard error) & (standard error) & (standard error) \\
\hline Percent of High School Graduates in College & $0.002^{* *}$ & -0.001 & 0.0001 \\
& $(0.0007)$ & $(0.002)$ & $(0.003)$ \\
Percent of Teachers with Graduate Degrees & $0.002^{* *}$ & $0.005^{\star *}$ & $0.003^{*}$ \\
& $(0.0006)$ & $(0.0014)$ & $(0.0019)$ \\
Average School Achievement & 0.001 & 0.005 & -0.008 \\
Average School SES & $(0.003)$ & $(0.007)$ & $(0.008)$ \\
& $0.154^{*}$ & -0.142 & 0.095 \\
& $(0.077)$ & $(0.223)$ & $(0.320)$
\end{tabular}


Table 2.

Gender Differences in Wages 38

Selection Adjusted Wage Estimates of School Effects

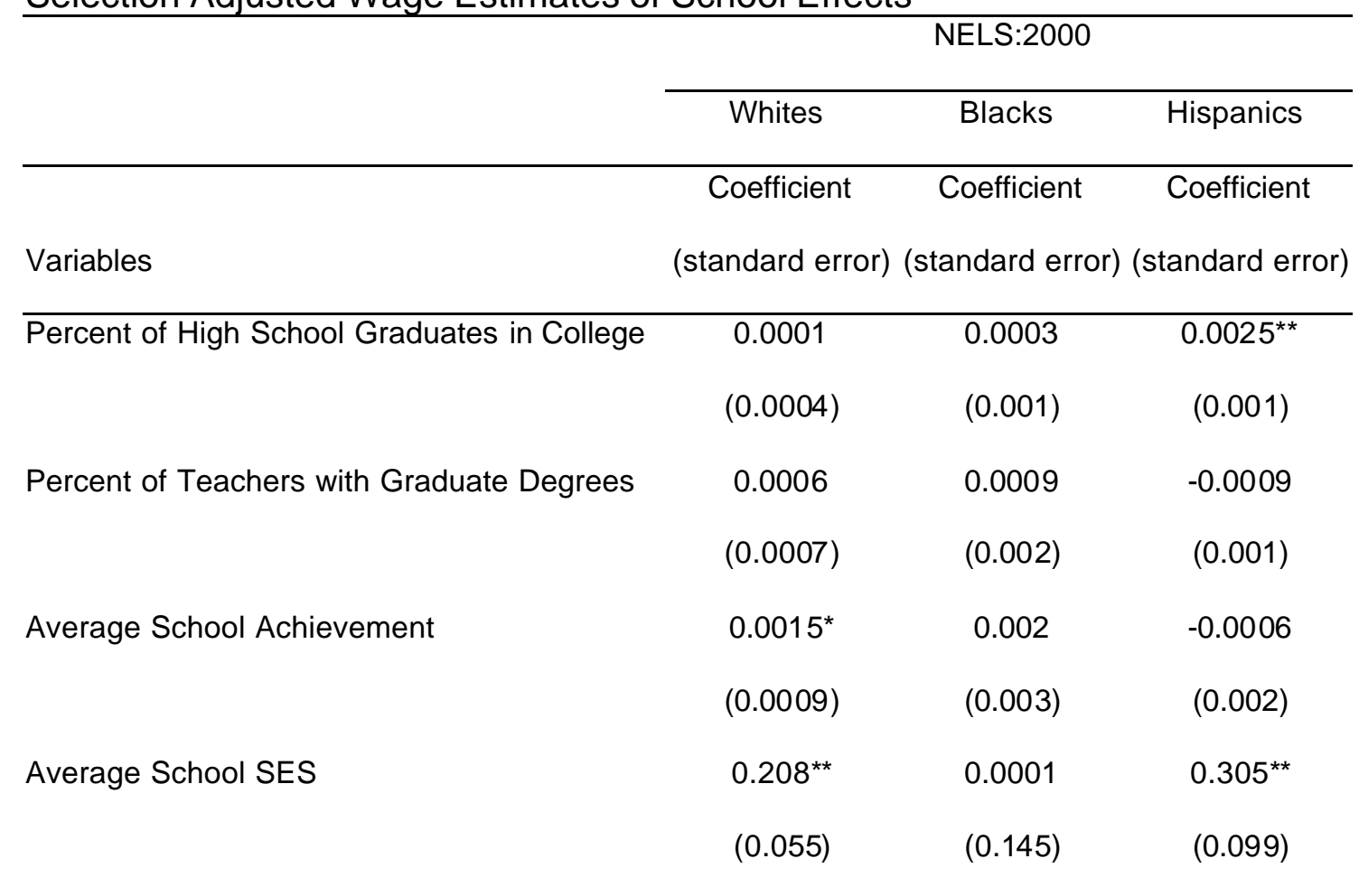

Note: standard errors are adjusted for heteroscedasticity

${ }^{*} p<0.05$ one-tail test

${ }^{* *} p<0.01$ one-tail test 
Gender Differences in Wages 39

Table 3.

Gender Differences in Hourly Wages: Quantile Regression Estimates

Whites

\begin{tabular}{|c|c|c|c|c|c|}
\hline Survey & Bottom $10 \%$ & Bottom 25\% & Median & Top 25\% & Top 10\% \\
\hline & $\begin{array}{l}\text { Coefficient } \\
\text { (st. error) }\end{array}$ & $\begin{array}{l}\text { Coefficient } \\
\text { (st.error) }\end{array}$ & $\begin{array}{c}\text { Coefficient } \\
\text { (st.error) }\end{array}$ & $\begin{array}{c}\text { Coefficient } \\
\text { (st.error) }\end{array}$ & $\begin{array}{l}\text { Coefficient } \\
\text { (st.error) }\end{array}$ \\
\hline NLS:79 & $\begin{array}{l}-0.056^{\star} \\
(0.026)\end{array}$ & $\begin{array}{c}-0.083^{\star *} \\
(0.012)\end{array}$ & $\begin{array}{c}-0.113^{\star *} \\
(0.014)\end{array}$ & $\begin{array}{l}-0.131^{* *} \\
(0.013)\end{array}$ & $\begin{array}{l}-0.157^{\star *} \\
(0.024)\end{array}$ \\
\hline NLS:86 & $\begin{array}{l}-0.047^{\star} \\
(0.024)\end{array}$ & $\begin{array}{l}-0.083^{\star *} \\
(0.017)\end{array}$ & $\begin{array}{l}-0.104^{\star *} \\
(0.013)\end{array}$ & $\begin{array}{l}-0.114^{* *} \\
(0.015)\end{array}$ & $\begin{array}{c}-0.112^{\star \star} \\
(0.017)\end{array}$ \\
\hline NELS:2000 & $\begin{array}{l}-0.051^{*} \\
(0.026)\end{array}$ & $\begin{array}{l}-0.048^{* *} \\
(0.018)\end{array}$ & $\begin{array}{l}-0.080^{\star *} \\
(0.014)\end{array}$ & $\begin{array}{c}-0.098^{\star *} \\
(0.023)\end{array}$ & $\begin{array}{l}-0.150^{* *} \\
(0.026)\end{array}$ \\
\hline
\end{tabular}

Blacks

\begin{tabular}{lccccc}
\hline Survey & Bottom 10\% & Bottom 25\% & Median & Top 25\% & Top 10\% \\
\hline & Coefficient & Coefficient & Coefficient & Coefficient & Coefficient \\
& (st.error) & (st.error) & (st.error) & (st.error) & (st.error) \\
\hline NLS:1979 & 0.042 & -0.036 & $-0.103^{\star \star}$ & $-0.153^{\star}$ & -0.137 \\
& $(0.050)$ & $(0.055)$ & $(0.035)$ & $(0.069)$ & $(0.088)$ \\
NLS:1986 & -0.062 & $-0.156^{\star *}$ & $-0.154^{\star \star}$ & $-0.113^{*}$ & $-0.266^{*}$ \\
& $(0.095)$ & $(0.052)$ & $(0.047)$ & $(0.058)$ & $(0.142)$ \\
NELS:2000 & $-0.194^{\star *}$ & -0.097 & $-0.115^{\star}$ & $-0.113^{\star *}$ & -0.045 \\
& $(0.077)$ & $(0.060)$ & $(0.050)$ & $(0.027)$ & $(0.067)$
\end{tabular}

Hispanics

\begin{tabular}{lccccc}
\hline Survey & Bottom 10\% & Bottom 25\% & Median & Top 25\% & Top 10\% \\
\hline & Coefficient & Coefficient & Coefficient & Coefficient & Coefficient \\
& (st.error) & (st.error) & (st.error) & (st.error) & (sta.error) \\
\hline NLS:1979 & 0.100 & 0.050 & 0.003 & 0.048 & 0.033 \\
& $(0.081)$ & $(0.059)$ & $(0.063)$ & $(0.075)$ & $(0.110)$
\end{tabular}


Gender Differences in Wages 40

Table 3.

Gender Differences in Hourly Wages: Quantile Regression Estimates

\begin{tabular}{lccccc}
\hline NLS:1986 & 0.072 & -0.060 & $-0.158^{\star \star}$ & $-0.121^{\star}$ & $-0.179^{\star}$ \\
NELS:2000 & $(0.078)$ & $(0.059)$ & $(0.067)$ & $(0.060)$ & $(0.096)$ \\
& 0.002 & 0.023 & -0.010 & $-0.121^{* \star}$ & -0.073 \\
& $(0.050)$ & $(0.042)$ & $(0.033)$ & $(0.030)$ & $(0.046)$
\end{tabular}

Note: standard errors are robust throug $\mathrm{h}$ bootstrapping

${ }^{*} p<0.05$ one-tail test

${ }^{* *} p<0.01$ one-tail test 
Table 4.

Gender Differences in Variability in Hourly Wages

\begin{tabular}{lccc}
\hline Survey & Whites & Blacks & Hispanics \\
\hline NLS:1979 & 1.069 & 0.819 & 0.840 \\
NLS:1986 & 0.982 & 0.968 & 1.417 \\
NELS:2000 & 1.071 & 0.972 & 0.702 \\
\hline
\end{tabular}

